\title{
RANCANG BANGUN SISTEM INFORMASI LOWONGAN KERJA BERBASIS WEB
}

\author{
Yusran $^{1}$, Lido Sabda Lesmana ${ }^{2}$, Firmasyah Putra ${ }^{3}$ Efri Yandani $S^{4}$ \\ ${ }^{1234}$ Universitas Dharmas Indonesia (UNDHARI) \\ 1yusran@undhari.ac.id, ${ }^{2}$ lidosabdalesmana11603@gmail.com,

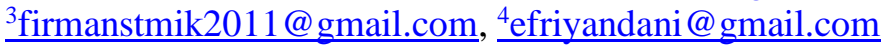

\begin{abstract}
ABSTRAK. Sistem informasi lowongan kerja berbasis web yang digunakan oleh masyarakat adalah untuk sebagai sumber informasi lowongan kerja yang menjadi kendala bagi orang yang ingin mencari pekerjaan. Jika dilihat dari peraturan pemerintah tentang perluasan kesempatan kerja maka pemerintah juga memiliki peran dalam mengatur bidang ketenagakerjaan. Sebagaimana dinyatakan dalam Peraturan Pemerintah Republik Indonesia Nomor 33 Tahun 2013, Pengangguran adalah masalah nasional dan merupakan tanggung jawab Pemerintah, Pemerintah Daerah, dan masyarakat, sehingga semua pemangku kepentingan harus terlibat secara bersama dan terintegrasi di seluruh sektor dan komunitas untuk memperluas peluang kerja baik di dalam maupun di luar hubungan kerja. Jadi untuk mendukung tujuan pemerintah mengenai ketenagakerjaan dan peran teknologi informasi, maka perlu dirancang dan dibangun media informasi untuk memberikan kemudahan bagi publik dalam memperoleh informasi pekerjaan. Salah satu media informasi berbasis internet yang dapat dimanfaatkan adalah situs web yang manfaatnya dapat diakses oleh pengguna untuk mendapatkan dan memenuhi kriteria lowongan kerja sesuai dengan kebutuhan perusahaan atau lembaga yang membutuhkan karyawan. Pengembangan sistem informasi ini menggunakan metode Waterfall, dengan bahasa pemodelan UML (Unified Modeling Language). Untuk pemrograman menggunakan bahasa pemrograman PHP dan MYSQL sebagai server basis data. Sistem informasi ini berbasis web, yang memiliki media penyimpanan terpusat di server database sehingga integritas data terjamin.
\end{abstract}

Kata Kunci: Lowongan Kerja, $U M L, W e b$

\begin{abstract}
The Web-based job vacancy information system that can be used by the community is for job vacancy information which has been an obstacle for people who want to find work. When viewed from government regulations concerning the expansion of employment opportunities that the government also has a role in regulating the employment field. As stated in the Government Regulation of the Republic of Indonesia Number 33 of 2013, Unemployment is a national problem and is the responsibility of the Government, Regional Government, and the community, so that all stakeholders must be involved in a joint and integrated manner across sectors and communities. strive to expand employment opportunities both within and outside the employment relationship. So to support the government's goals regarding employment and the role of information technology, it needs to be designed and built an information media to provide convenience for the public in obtaining job information. One of the internet-based information media that can be utilized is a website whose benefits can be accessed by users to get and fulfill the criteria for job vacancies in accordance with the needs of companies or agencies that need employees. The development of this information system uses the Waterfall method, with the UML (Unified Modeling Language) modeling language. For programming using the programming language PHP and MYSQL as the database server. This information system is web based, which has a centralized storage media in a database server so that data integrity is guaranteed.
\end{abstract}

Keywords: Job Vacancies, UML, Web

\section{PENDAHULUAN}

Sistem dapat didefinisikan sebagai sekumpulan objek- objek yang saling berelasi dan berinteraksi, serta hubungan antar objek bisa dilihat sebagai satu kesatuan yang dirancang untuk mencapai satu tujuan yang telah ditetapkan (Rochman et al., 2018). Sistem informasi merupakan suatu kebutuhan yang sangat penting saat ini karena seiring dengan perkembangan teknologi informasi bahwa semua informasi bisa didapatkan kapanpun dan dimanapun kita berada. Untuk sebuah sistem yang dipakai dan diterapkan dalam kegiatan sehari-hari, pasti ada kelebihan dan ada kekurangannya. Karena sistem informasi saat ini yang paling cepat dan akurat informasinya adalah sistem informasi berbantuan teknologi internet. Dengan adanya internet ini membuat pengguna sistem lebih puas dan cepat untuk mendapatkan informasi. Akan tetapi dibalik kelebihannya yang bagi pengguna bisa memanfaatkannya dimanapun, kapanpun dan dalam kondisi apapun, kekurangannya adalah pengguna akses internet harus siap selalu terhubung dan terkoneksi dengan jaringan internet agar bisa memaksimalkan sumber daya teknologi informasi berbasis internet tersebut. 
Jika dilihat dari peraturan pemerintah yang sudah dituangkan pada Peraturan pemerintah nomor 82 tahun 2012 pada BAB 1 Pasal 1 tentang Informasi Elektronik adalah satu atau sekumpulan data elektronik, termasuk tetapi tidak terbatas pada tulisan, suara, gambar, peta, rancangan, foto, electronic data interchange (EDI), surat elektronik (electronic mail), telegram, teleks, telecopy atau sejenisnya, huruf, tanda, angka, kode akses, simbol, atau perforasi yang telah diolah yang memiliki arti atau dapat dipahami oleh orang yang mampu memahaminya. Sehingga teknologi informasi tersebut bisa dimanfaatkan untuk beberapa aktifitas dan kebutuhan untuk masyarakat yang membutuhkannya.

Lapangan pekerjaan ialah suatu kondisi posisi kegiatan peusahaan atau pemerintah yang kosong sehingga memerlukan seseorang untuk mengisi posisi tersebut guna membantu menjalankan kegiatan operasional perusahaan menjadi lebih baik (Taqwiym \& Wijaya, 2017). Sistem informasi lowongan kerja berbasis Web yang bisa dimanfaatkan bagi masyarakat adalah untuk informasi lowongan pekerjaan yang selama ini menjadi kendala bagi masyarakat yang ingin mencari pekerjaan. Jika dilihat dari peraturan pemerintah tentang perluasan kesempatan kerja bahwa pemerintah juga mempunyai peran dalam mengatur lapangan pekerjaa. Seperti yang tertuang pada Peraturan pemerintah Republik Indonesia Nomor 33 Tahun 2013 adalah Pengangguran merupakan masalah nasional dan merupakan tanggung jawab Pemerintah, Pemerintah Daerah, dan masyarakat, sehingga dalam penanggulangannya harus dilakukan oleh semua stakeholders terkait secara bersama dan terintegrasi antar lintas sektor dan masyarakat, dengan cara mengupayakan perluasan kesempatan kerja baik di dalam maupun di luar hubungan kerja.

\section{METODE PENELITIAN}

\subsection{Desain Penelitian}

Pengembangan sistem informasi ini menggunakan metode Waterfall, dengan bahasa pemodelan $U M L$ (Unified Modeling Language). Untuk pemrogrammannya menggunakan bahasa pemrogramman PHP dan MYSQL sebagai database servernya. Sistem informasi ini berbasis web, yang memiliki media penyimpanan terpusat di dalam sebuah database server sehingga integritas data lebih terjamin. Untuk menghindari kesalahan dalam input data, sistem ini dapat menampilkan beberapa informasi penting untuk syarat-syarat lowongan kerja khususnya pada wilayah kabupaten dharmasraya.

Metode pengembangan sistem yang digunakan yaitu waterfall adalah sebuah metode yang sistem untuk penyelesaian sistemnya seperti air terjun yaitu awali dari analisis, Desain/perancangan, Pengodean/Implementasi dan pengujian.

\section{Analisis}

Pada tahap ini adalah langkah awal bagi peneliti untuk mengumpulkan data ataupun referensi yang sesuai dengan kebutuhan peneliti dalam merancang dan membangun sistem informasi lowongan kerja. Karena untuk merancang dan membangun sistem informasi lowongan kerja, harus mengetahui terlebih dahulu informasi apa yang akan dibutuhkan oleh pengguna dan kemudian medesainnya ke dalam bentuk sebuah sistem yang mudah dipahami oleh user/pengguna sistem.

\section{Desain/Perancangan}

Desain/perancangan adalah langkah lanjutan dari kegiatan awal dalam membangun sebuah sistem informasi. Berdasarkan dari data yang dibutuhkan oleh pengguna sistem/user maka peneliti melakukan desain halaman web agar mudah digunakan dan dipahami oleh pengguna. Dalam penelitian ini, peneliti melakukan perancangan untuk lowongan kerja bagi pengguna ataupun pengunjung yang membutuhkan sumber informasi tentang lowongan kerja pada perusahaan ataupun instansi tertentu berbasis web.

3. Pengodean/Implementasi

Pengodean/Implementasi adalah langkah lanjutan dari perancangan karena pengodean adalah melakukan coding pada untuk halaman web sesuai dengan perancangan ataupun layout yang telah didesain dan dirancang pada langkah-langkah sebelumnya. Pada langkah ini, dimulai dari coding sampai dengan di jalankan dengan berbantuan program Xampp.

\section{Pengujian}

Langkah pengujian ini merupakan uji coba terhadap sistem atau program setelah selesai dibuat untuk mengetahui apakah sistem yang baru dapat berjalan dengan baik dan sudah sesuai dengan kebutuhan pengguna sistem atau belum.

\subsection{Analisis SWOT}

Analisis SWOT adalah analisis yang membahas beberapa peluang ancaman untuk merancang dan membangun sistem informasi Lowongan Kerja di Kota Batam adalah sebagai berikut: 
1. Kekuatan (Strength)

a. Untuk informasi kesempatan atau lowongan kerja masih di informasikan dengan cara manual pada Mading.

b. Biaya yang dikeluarkan relatif lebih murah karena karena bisa mendapatkan informasi kapanpun dan dimanapun karena sistem ini dimanfaatkan secara online.

2. Kelemahan (Weakness)

a. Sistem informasi ini dirancang dan dibangun belum bisa diimplementasikan secara maksimal karena pencari kerja masih terpusat pada Mading yang ada pada perusahaan yang membuka lowongan kerja.

b. Belum bisa menampilkan seluruh informasi lowongan kerja dari seluruh perusahaan yang ada di Kota Batam.

3. Peluang (Opportunity)

a. Untuk data perusahaan yang membuka lowongan kerja akan disimpan dalam database.

b. Bisa memberikan informasi lowongan kerja yang dibutuhkan dengan cepat dan akurat.

4. Ancaman (Threat)

a. Muncul sistem baru yang lebih baik dan lebih efisien.

b. Tidak update-nya data karena kurangnya disiplin dan tanggung jawab pengguna sistem.

\section{PEMBAHASAN}

Informasi lowongan kerja menjadi kendala oleh pencari kerja dan informasipun masih diumumkan secara manual atau dipajang pada madding. Untuk mempermudah pencari kerja atau pelamar dalam mendapatkan informasi, maka peneliti mencoba untuk merancang sistem informasi lowongan pekerjaan secara online Berdasarkan dari data-data survey ataupun wawancara yang telah dilakukan dilapangan. Dengan adanya sistem informasi lowongan pekerjaan secara online ini diharapkan bisa membantu dan mempermudah antara perusahaan yang membuka lowongan dengan pelamar pekerjaan dalam proses informasi lowongan pekerjaan. Dengan adanya desain sistem, admin bisa merancang sistem sesuai dengan kondisi dan kebutuhan dari pengguna sistem termasuk tool dan tampilan halaman web yang akan dibangun. Proses pengajuan surat lamaran pekerjaan tidak memerlukan waktu yang cukup lama. Selain itu, sistem informasi yang baru adalah sistem informasi berbasis web, dimana akan terhubung dengan jaringan internet, dengan ini akan memudahkan setiap pengguna yang mempunyai otorisasi untuk mengakses segala informasi yang telah disediakan tanpa harus mendatangi lokasi pengumuman lowongan pekerjaan.

\subsection{Unified Modeling Language (UML)}

Pada perkembangan teknik pemograman berorientasi objek, munculah sebuah standarisasi bahasa pemodelan untuk pembangunan perangkat lunak yang dibangun dengan menggunakan teknik pemograman berorientasi objek yaitu Unified Modeling Language (UML)(Abdurahman et al., 2014).

\section{a. Use Case}

Berikut ini adalah diagram use case yang menunjukkan fungsi antara admin, Pemberi Berita dan user sehingga dapat melakukan kegiatan berbagi berita.

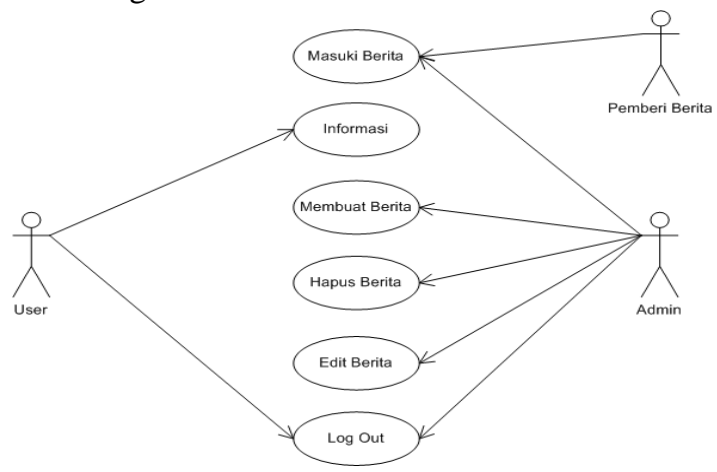

Gambar.1 Use case diagram

\section{b. Diagram Aktifitas}

Berikut ini adalah diagaram aktifitas yang menunjukan fungsi admin dan personalia pada sistem informasi lowongan pekerjaan. Pada diagram aktifitas ini menjabarkan beberapa proses kegiatan didalam sebuah sistem. 


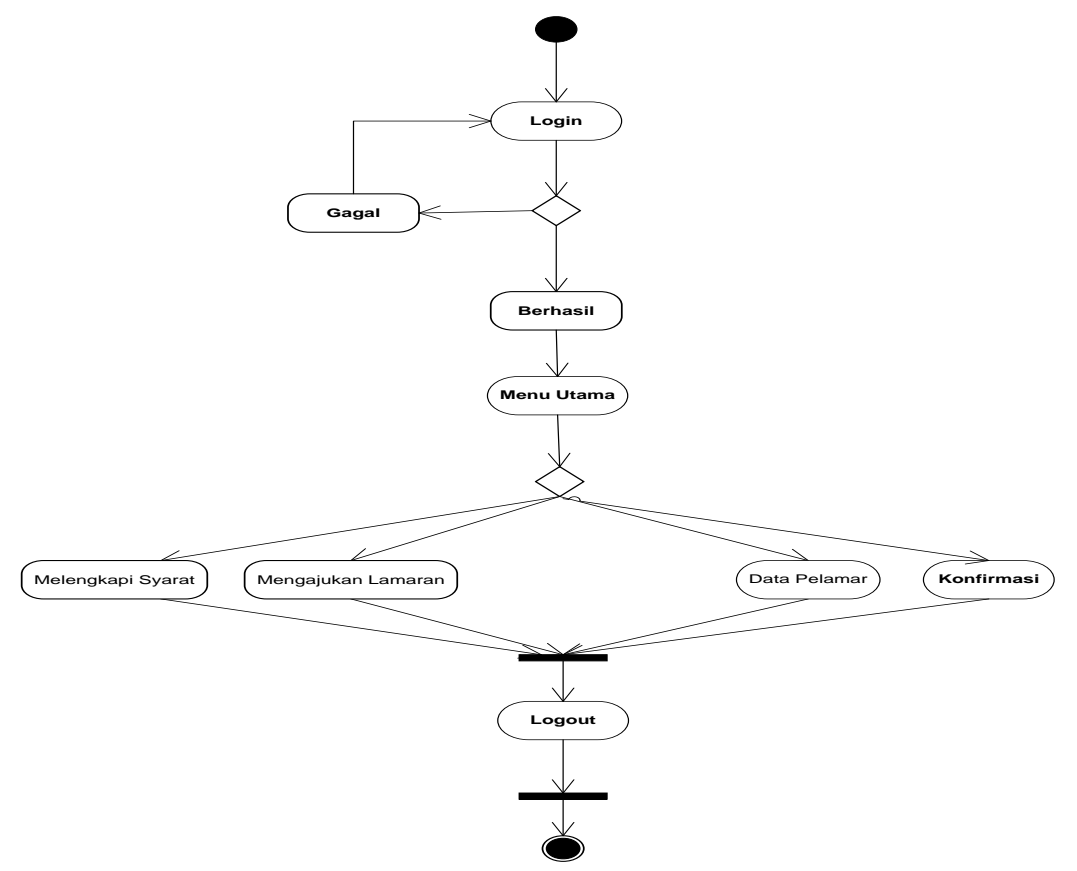

Gambar.2 diagram aktifitas user

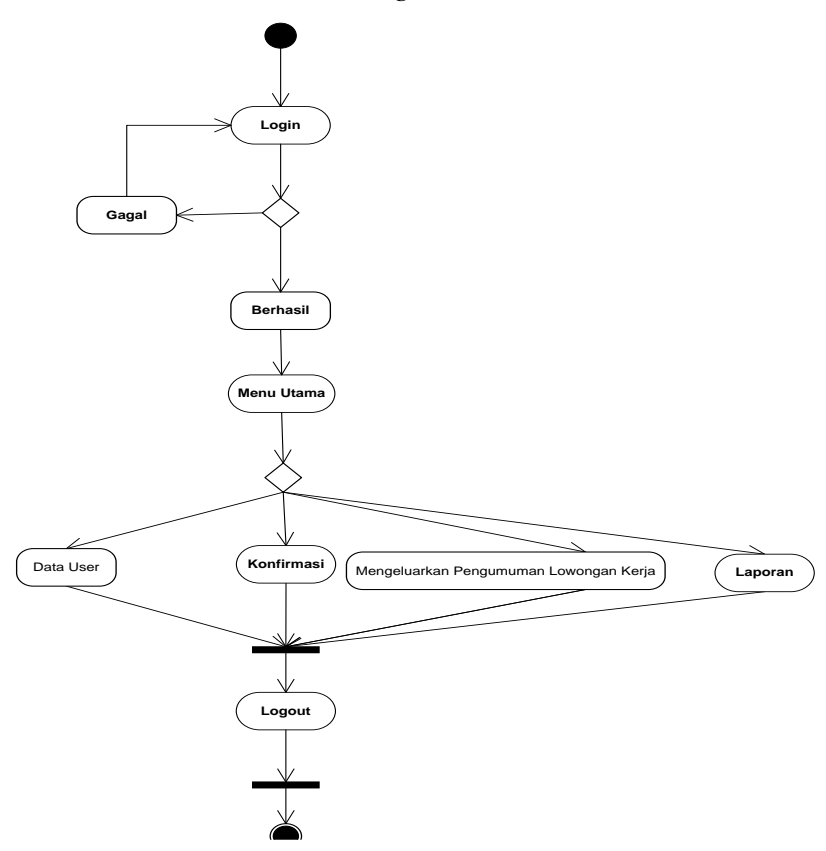

Gambar.3 diagram aktifitas admin

\section{c. Rancangan Layar Masukan}

Pada halaman home ini user akan bisa melihat tampilan depan dari halaman web lowongan pekerjaan. Dengan adanya rancangan ini diharapkan pengguna dapat melakukan kegiatan melihat dan memilih informasi lowongan pekerjaan. 


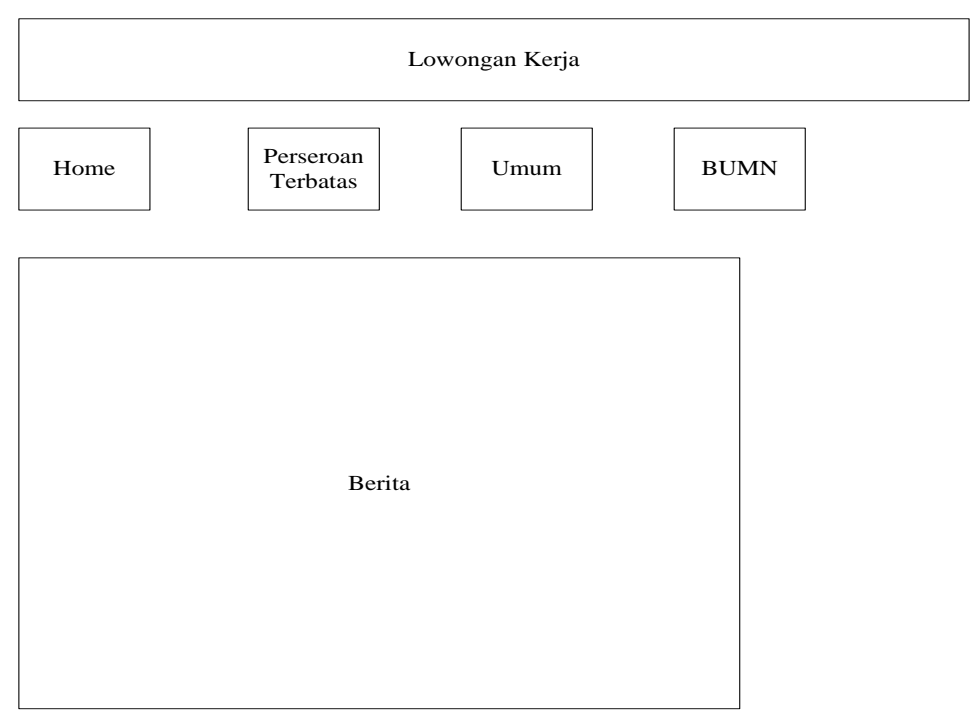

Gambar 4. Halaman Dashboard

Halaman login berguna untuk pengunjung pertama pada halaman web. Tujuannya adalah untuk mengetahui data pengguna sistem yang berlangganan pada website Lowongan Pekerjaan.

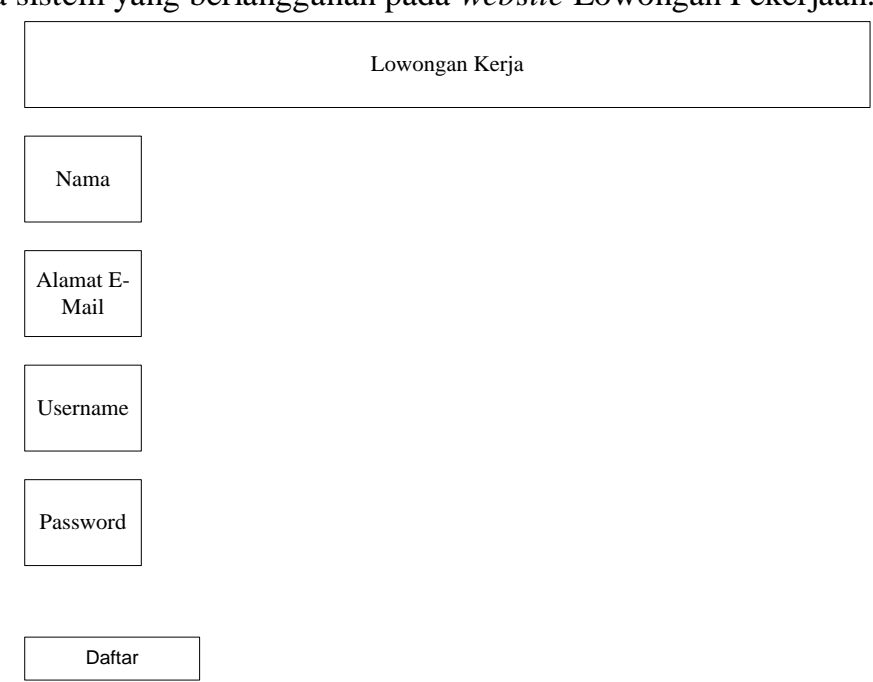

Gambar 5. Halaman login

\section{KESIMPULAN}

Berdasarkan dari hasil analisis, perancangan dan pembuatan program aplikasi yang telah diuraikan pada bab sebelumnya, maka dapat diambil beberapa kesimpulan sebagai berikut:

1. Sistem informasi lowongan kerja secara online berbasi web bisa dimanfaatkan oleh beberapa perusahaan yang akan membuka lowongan pekerjaan dan dengan bantuan pemrogramman $P H P$

2. dan MySQL sebagai database servernya.

3. Sistem yang baru ini juga bisa diakses oleh pengguna atau pencari kapan saja dan di mana saja untuk mendapatkan informasi lowongan pekerjaan.

Proses penyebaran informasi lowongan kerja bisa dimanfaatkan oleh pencari kerja dan perusahaan yang membuka lowongan pekerjaan

\section{DAFTAR RUJUKAN}

Abdurahman, H., Riswaya, A. R., \& Id, A. (2014). Aplikasi Pinjaman Pembayaran Secara Kredit Pada Bank Yudha BHakti. Aplikasi Pinjaman Pembayaran Secara Kredit Pada Bank Yudha BHakti, 8(2), 61-69. http://jurnal.stmik-mi.ac.id/index.php/jcb/article/view/114/138 Rochman, A., Sidik, A., \& Nazahah, N. (2018). Perancangan Sistem Informasi Administrasi Pembayaran 
SPP Siswa Berbasis Web di SMK Al-Amanah. Jurnal Sisfotek Global, 8(1), 51-56. https://doi.org/10.1002/ijc.23959

Taqwiym, A., \& Wijaya, N. (2017). Perancangan Lowongan Kerja Online Berbasis Web Pada Pt Anh. Jurnal Ilmiah Informatika, 2(1), 112-116. https://doi.org/10.35316/jimi.v2i1.461 